\title{
E-Commerce In China And Its Risks And Opportunities For US Companies
}

\author{
Ki Hee Kim, (Email: KimK@wpunj.edu), William Paterson University \\ Lin W. Leung, BMCC-CUNY \\ C. K. Leung, (Email: LeungC@wpunj.edu), William Paterson University
}

\begin{abstract}
China is the fastest growing Internet economy in Asia/Pacific, with Chinese Internet users forecasted to account for approximately half of all Internet usage in the region by the end of 2005. Chinese companies are also proving to be the largest investors of Internet infrastructure equipment as they turn to the Internet to increase business and information flow. As the Internet permeates all corners of the globe, small to medium-sized businesses may be pondering the move to a multilingual ecommerce website to increase their reach, and may be enticed by the potentially huge Chinese market. While a larger corporation can make the transition to a multilingual site with relative ease, small to medium enterprises (SMEs) must be concerned about the cost and effort involved, as well as how to go about the actual translation process and handle complications. China's accession into the World Trade Organization (WTO) has opened up many opportunities, especially to expand their operations in the outside world, and has also changed it from a minor trading country to one of the world's major trading countries. Some companies are already starting to take advantage of these opportunities, making now the key time to get a foothold in the market before everyone else makes their claim. The countries as a whole and its individual companies begin to face a range of issues that will have a direct impact on the course of the country's further development. This research paper will examine business environment in China for US companies to analyze risks and opportunities of E-commerce in China.
\end{abstract}

\section{INTRODUCTION}

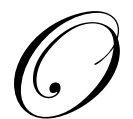

nline merchants have the advantage of being able to reach a global customer base twenty-four hours a day, seven days a week. The opportunity to shop on the internet is virtually unrestricted, as the internet removes such barriers to retail shopping as limited store operating hours and the inability of some customers to get to a conveniently located outlet. As the internet permeates all corners of the globe, small to mediumsized businesses may be pondering the move to a multilingual ecommerce website to increase their reach, and may be enticed by the potentially huge Chinese market. The number of Chinese internet users rose to 120 million by the end of 2004, making China one of the world's top three online populations and further driving the grown of ecommerce, according to the 'E-commerce in China' report. The number of internet users is expected to increase by $5 \%$ every year. E-commerce has become an economic phenomenon that broadly affects the production, exchange, distribution, and consumption of products and services all around the world. China is one of those countries that it is still adjusting with its new development strategies, and still has to face many other challenges in E-commerce. Under the pressure of E-commerce, many inefficient distribution channels will be weakened or even eliminated, while many more efficient ones will be introduced and enhanced. Many industries are still meeting consumer's rejections against E-commerce. Therefore, the issue facing China is not to worry about this kind of rejection and disappearance, but how to face challenges, grasp potential chances, and advance E-commerce.

\section{DEFINITIONS OF E-COMMERCE}

Business can be defined as the organized effort of individuals to produce and sell, for a profit the products and services that satisfy society's needs. In a simple sense, then, e-business (electronic business) can be defined as the 
organized effort of individuals to produce and sell through the facilities available on the Internet. Defining Ecommerce in too generalized a sense may have disadvantages. A transaction can be called E-commerce as long as the whole business chain involves some electronic formats. According to this definition, any business activities can be called ecommerce if the transaction contains on of the following formants: Sometimes people use the term Ecommerce instead of e-business. This would include electronic data exchange, electronic cashiers, electronic ordering systems, or even telephones, telex and telegrams. In a strict sense, E-commerce refers to all business activities conducted on the Internet by an individual firm or industry; likewise E-commerce is a part of e-business activities involved in buying and selling on line. We generally use the term e-business because of its broader definition and a scope.

\section{FUNDAMENTAL MODELS OF ECOMMERCE}

\section{Business-To-Business}

Many ecommerce can be distinguished from others simply by their customer focus. For instance, some firms use the internet mainly to conduct business with other businesses. These firms are generally referred to as having a business-to-business (B2B) model. Currently the vast majority of ecommerce is B2B in nature.

\section{Business-To-Consumer Model}

In contrast to those firms using a B2B model, firms like Amazon.com and eBay are clearly focused on individual buyers and so are referred to as having a business-to- consumer (B2C) model. In a B2C model, understanding how consumers behave online is critical to the firm's success. The internet has enhanced firms' ability to build good customer relationships.

\section{Consumer-To-Consumer Model}

Unlike the B2B and B2C models, which focus on business transactions and communications, the consumerto-consumer(C2C) model involves the increasingly popular use of peer-to-peer software that facilitates the exchange of data directly between individuals over the internet.

\section{GLOBAL IMPACTS AND PROBLEMS OF ECOMMERCE}

The internet is based on electronic connections between millions of computers, servers, and local networks located around the world, linked together by technical protocols that are both synchronized and decentralized. With an estimated 655 million people wired worldwide and more than 28 billion web sites, businesses have increasingly moved many services and transactions on line. In many respects, technical knowledge and expertise has become vastly more important firm an economic standpoint than otherwise non-technical forms of offline labor.

Responding to a variety of social and economic forces, corporate executives have opted to create semiautonomous units, joint partnerships, and other kinds of small-scale contractual arrangements. Such companies have attempted to facilitate quicker response times to micro-economic market developments by devolving power and decision-making. Such trends have fueled the creation of "virtual corporations," i.e., autonomous actions engaged in temporary partnerships online. Significantly, business-to-business (B2B) E-commerce has shown a much faster growth rate than the business-to-consumer variety. However, it is important to note that there are many potential downsides to this new wired world. One of the most serious weaknesses of the internet is that it seems to lack any reliable means for filtering the massive amounts of information available online. Too much information coming from too many questionable or dubious sources raises significant problems of discernment for most online consumers. In terms of E-commerce, serious concerns have been raised about fraud, privacy incursions, information security, spamming, copyright infringement, trademark violations, the sale of goods and services banned in some jurisdictions, and inadequate or vaguely defined consumer protection laws. According to research by the University of Denver's Privacy Foundation Workplace Surveillance Project, more than one-third of the 40 million U.S. employees who work online-about 14 million-are under continuous surveillance by their employers, using commercially available software. 
Because the opportunity to monitor behaviors is there, it is done-regardless of whether it is really productive in any way.

\section{E-COMMERCE DEVELOPMENT IN CHINA}

In March 6, 1998, the Beijing Century Intercom Technology Company sold its first item over the internet; it was also the first on-line sale in China's business history. While E-commerce was stepping its takeoff stage in the U.S., the development of China's E-commerce was only in its infant stage. China has more than 60 million mobile phone users and as many as 97 million internet users in 2004. The number is second only to that in the United States. While China may be lucrative for U.S. businesses, doing business in China is challenging. According to Norman Page, partner-in-charge of DWT's China Practice Group, "China presents a dilemma for U.S. companies of all kinds, including internet-based companies. Doing business there can be very frustrating. On the other hand, companies that choose to ignore China now are running the risk of loosing out for a long time on the tremendous potential that the China market represents." "The challenges are clear, "said speaker Stephen Anderson, Commercial Attaché' with the Foreign Commercial Service at the American Embassy in Beijing. One of the crucial factors related to the growth of E-commerce in China is the online population. Also, the drastic increase of PC population is a result of the PC's everincreasing performance/price ratio and decreasing software development costs. In addition, information infrastructure also plays an important role in the growth of E-commerce.

\section{CONSTRAINTS ON CHINA'S E-COMMERCE DEVELOPMENT}

Despite the creation of two new business-to-consumer (B2C) or business-to-business (B2B) sites each day in China, the total value of online advertising and e-business transactions are small. An average of 63.1 out of 10,000 of the world's commuters is connected mainframes; in China the figure is only 0.16 according the World Bank statistics. The numbers of computer software and hardware professionals in China are 12.5 percent and 6.25 percent, respectively, out of the total number of employees in the information industry. In developed countries, the number of employees in the IT sector can be more than 50 percent of the labor force, while the information industry can account for more than 50 percent of the growth of the national economy. There are many other barriers that hinder the faster expansion of E-commerce in China, some factors are illustrated below:

- $\quad$ The greatest weakness in the Chinese market is the embryonic state of B2B development. Most E-commerce activities remain focused on Business-Consumer (B2C) transactions, but there is very little B2B activity.

- Low level of credit card and internet penetration (less than $1 \%$ of the population). The viability of many of China's e-business model is uncertain.

- Most E-commerce models in China are rudimentary. The strategy is simply to build a site, hope to attract visitors and worry about how to make money later. Many sites are a mere copy other pages from overseas.

- Most consumer websites in China are E-commerce sites in name only, with shoppers taking orders online but paying offline, usually cash-on-delivery. Moreover, most sites maintain traditional relationships with inefficient suppliers and distributors.

- $\quad$ Prices are often uncompetitive, too, and service standards are poor. China's E-commerce vendors cannot provide the benefits that customers in other countries have learned to expect, such as reduced prices that are usually lower than those found in conventional stores, superior service including 24-hour, seven-day-per week hours as well as reliable delivery systems. It is not surprising, therefore, according to one survey, that just $40 \%$ of the online buying public said they ere satisfied with internet shopping(versus $90 \%$ globally).

- $\quad$ E-commerce in China also lacks depth: The portal market is just taking its first steps-the main goal is to attract people's attention. Last year online sales reached a mere $\$ 6.5$ million, equivalent to $0.018 \%$ of China's total retail sales (versus $1.4 \%$ in the US).

- $\quad$ Most local domestic firms lack the marketing expertise, financial strength, technology, and service standards that international B2B can bring.

- High connection fees demanded by local internet service provide with a serious obstacle to the development of E-commerce. 
- $\quad$ Another factor that hinders E-commerce growth is that people in China lives in an environment where so much importance is attached to savings. The Chinese have the highest personal savings rate of any country and not living on credit.

- Security. Consumers mistrust online merchants and the concept of secure electronic payment. Online shoppers were concerned with security. With respect on line business' security, 55.5 percent of businesses have no firewall, 64.9 percent have no security auditing system, 67.2 percent have no invasion monitoring system, and 72.3 percent have no automatic recovery system.

- Government department in China, as the largest owners and users of IT, lag in developing and utilizing information resources.

- At the practical level, Chinese consumers prefer to transact in cash or debit cards. Shopping is a hobby to them; they would prefer buying things in person.

- $\quad$ Many people are worried that the development of E-commerce in China would replace the traditional retail and wholesale business.

- $\quad$ The Chinese government also views the internet with some suspicions.

- $\quad$ Chinese laws and regulations are not hospitable environment for the development of E-commerce.

- $\quad$ E-commerce is subject to the scrutiny by government agencies at both the central and local government levels.

- $\quad$ China's currency is not yet freely convertible.

- $\quad$ The most contentious problems are with tariffs and taxations.

\section{MARKET POTENTIALS AND ITS RISKS OF E-COMMERCE IN CHINA}

Chinese government is paying increasing attention to the development of E-commerce. Chinese government has pointed out that E-commerce represents the future direction of business development and will bring more business opportunities into China. The government would consider E-commerce as a way to increase the efficiency of many low-performing state-owned enterprises which are being reformed. Also, Chinese government as well as Chinese companies is expected to take advantages of the global internet technology to increase international trade. They are:

- $\quad$ Exponential growth in E-commerce trade leading to overall increases in world trade.

- 80 percent of E-commerce growth will be in B2B. Therefore, more B2B business is expected in China in the future.

- $\quad$ Could lead to faster transfer of technology into China.

- $\quad$ Access to more information regarding markets, opportunities, and supply chains.

- $\quad$ Chinese companies can assist in overcoming the drawback of distance from developed markets.

- $\quad$ Chinese companies could reduce the role of middlemen, intermediaries, agents etc.

- $\quad$ Chinese companies can reduce labor costs by using more E-commerce.

- $\quad$ Chinese consumers are able to get lower priced items

- $\quad$ Chinese companies can reduce delivery costs.

- $\quad$ Chinese companies must improved efficiencies to compete with MNEs.

- $\quad$ More B2G (business-to-government) are expected in China.

- $\quad$ Chinese companies must have competitive advantages by providing e-services.

- $\quad$ E-commerce can be the bridge to overcoming the drawback of distance form developed markets and Chinese companies have potentials for providing world-wide presence by using more E-commerce.

- $\quad$ E-commerce provides the best platform for innovativeness. It combines the efficiencies of information technology and software with the global advantages of the digital economy. Chinese companies will benefit from these advantages.

China can take advantages through E-commerce such as:

- $\quad$ Customized shopping cart applications and integrated product information pages.

- $\quad$ Virtual store fronts with searchable online catalog.

- $\quad$ An internet browser friendly index and hierarchical listing for multiple-level product categories. 
- Integration of online store with existing site.

- Secure and customized administrative interfaces.

- $\quad$ Online customer support services and call centers.

- Secure credit card transaction processing.

- $\quad$ Fully integrated E-commerce data marts for customer profiling, relationship management, and to facilitate marketing decision process. in China.

Clearly, we can see the high interests of both the government and business sectors in promoting E-commerce

\section{CONCLUSION}

The coming years promise to be an interesting period in the development of China's E-commerce. On the one hand, efforts on the part of various local and central government agencies to regulate areas of the internet that affect them can be expected to accelerate; therefore, we can expect more regulations of the kind already issued. At the same time, the Chinese government is likely to step up efforts to regulate E-commerce in a more integrated fashion. According to the report, the guidelines include a discussion of comprehensive changes needed to China's legal system in order to support the development of E-commerce. Foreign companies can also be expected to become increasingly interested in China E-commerce. This is in part a natural extension of he growth of the Chinese market. E-commerce in China should have considerable growth as China continues to embrace international trade practices and increasing presence of online activities in the future.

\section{REFERENCES}

1. $\quad$ Bran Canzer, E-Business: Strategic Thinking \& Practice, $2^{\text {nd }}$ edition, Houghton \& Mifflin, 2006.

2. Diana F. Rojas, Ecommerce in China: Evolution, History, and Future Perspectives, December 2002.

3. David Drissel, Extraterritorial Regulations of Internet Commerce: Strategies for Translantic Harmonization, August 2004.

4. James A. O'Brien, Introduction to Information Systems, $12^{\text {th }}$ edition, McGraw-Hill.

5. http://www.idc.com/getdoc.jsp?containerId=IDC-p1623, bitpie, Sept. 7. 2004.

6. http://www.nua,com/surveys/if=US \&art-id=905355970 \& rel=true.

7. http://www.eletra.com/ecomma/e-article000012163.cfm.

8. http://www.ilo.or/public/english/bureau/inst/papers/2000/dp1231.

9. http://www.southcentre.org/publications/ecommerce/-05htm.

10. The Future of Ecommerce in China, www.estwetcenter.org.

11. http://www.chinaline-com/issues/internet-policy/13100092825.asp.

12. http://www.ucs.mun.ca/-z94x2/ecomm.htm.

13. US the Department of Commerce (DOC), webpage:www.doc.gov.

14. http://www.bitipe.com/data/detail?id=1002725801-566\&type=REX\&x=1985799311. 


\section{NOTES}

